\title{
Effects of Ti content on dielectric and energy storage properties of $\left(\mathrm{Pb}_{0.94} \mathrm{La}_{0.04}\right)\left[\left(\mathrm{Zr}_{0.70} \mathrm{Sn}_{0.30}\right)_{1-x} \mathrm{Ti}_{x}\right] \mathrm{O}_{3}$ ferroelectric/antiferroelectric ceramics
}

\author{
Ran Xu, Jingjing Tian, Yujun Feng, Xiaoyong Wei and Zhuo Xu* \\ Electronic Materials Research Laboratory, Key Laboratory of the Ministry of Education \\ Xi'an Jiaotong University, Xi'an, Shaanxi 710049, P. R. China \\ *xuzhuo@xjtu.edu.cn
}

\begin{abstract}
Received 19 October 2016; Revised 12 November 2016; Accepted 14 November 2016; Published 12 December 2016
Ferroelectric/antiferroelectric (FE/AFE) ceramics with composition of $\left(\mathrm{Pb}_{0.94} \mathrm{La}_{0.04}\right)\left[\left(\mathrm{Zr}_{0.70} \mathrm{Sn}_{0.30}\right)_{1-x} \mathrm{Ti}_{x}\right] \mathrm{O}_{3}$ were fabricated via solid state reaction and the effects of Ti content on dielectric and energy storage properties were studied. High releasable energy density of $1.03 \mathrm{~J} / \mathrm{cm}^{3}$ was obtained when $x=0.12$ under $65.7 \mathrm{kV} / \mathrm{cm}$. With increasing Ti content, both the forward and backward phase transition fields would decrease. When $x=0.16$, the dielectrics would be under FE state at room temperature $\left(22^{\circ} \mathrm{C}\right)$ and the phase transition from FE to AFE and then to paraelectric (PE) was observed with temperature rise. The discharge properties were also studied and the results proved that the stored charge in AFE could be released much more completely than that in FE.
\end{abstract}

Keywords: Antiferroelectrics; energy storage; phase transition; dielectric properties; discharge properties.

\section{Introduction}

Capacitors are the most commonly used devices for energy storage in power electronics and pulsed power systems. The development of capacitors has been promoted by these developing fields. ${ }^{1,2}$ Generally, the capacitors should be with high energy density, high fatigue resistance, high temperature stability and fast discharge time, etc. ${ }^{1-5}$ High energy storage density is the key to the miniaturization of power electronics and pulsed power systems and high fatigue resistance is required to ensure the repetitive charge-discharge operation for capacitors. ${ }^{6}$ Temperature stability is important for systems which operate in a wide temperature range. ${ }^{3}$ Unlike batteries, capacitors should be with much faster discharge time, especially in pulsed power systems. ${ }^{7}$

Consequently, as the main part of capacitors, dielectrics with high performance are greatly needed to meet the above requirements. Among several types of dielectrics, antiferroelectrics (AFEs) are good candidates due to their high energy density, fast discharge speed, good fatigue resistance, low remanent polarization. ${ }^{3,5,6,8}$ In the past decades, AFE materials have been investigated widely for dielectrics of capacitors. Especially, the La-modified lead zirconate titanate stannate (PLZST) material systems has been studied most frequently for their great potential. Usually, their performance could be improved by composition variation, such as the La content, ratio between $\mathrm{Zr}$ and $\mathrm{Sn}$, and the Ti content. For example, Feng et al. studied the effects of La modifier on the dielectric properties of $\left(\mathrm{Pb}_{1-3 x / 2} \mathrm{La}_{x}\right)\left(\mathrm{Zr}_{0.55} \mathrm{Sn}_{0.30} \mathrm{Ti}_{0.15}\right) \mathrm{O}_{3}$ ceramics and found that increasing La content would result in transformation from ferroelectric (FE) to AFE phase and narrow the hysteresis loop. ${ }^{9}$ Jiang et al. fabricated
$\left(\mathrm{Pb}_{0.858} \mathrm{Ba}_{0.1} \mathrm{La}_{0.02} \mathrm{Y}_{0.008}\right)\left(\mathrm{Zr}_{0.65} \mathrm{Sn}_{0.3} \mathrm{Ti}_{0.05}\right) \mathrm{O}_{3^{-}}\left(\mathrm{Pb}_{0.97} \mathrm{La}_{0.02}\right)$ $\left(\mathrm{Zr}_{0.9} \mathrm{Sn}_{0.05} \mathrm{Ti}_{0.05}\right) \mathrm{O}_{3}$ AFE composite ceramics and energy storage density as high as $4.65 \mathrm{~J} / \mathrm{cm}^{3}$ could be obtained. ${ }^{10}$ Other methods such as glass addition, ${ }^{11}$ hot press sintering, ${ }^{12}$ spark plasma sintering ${ }^{13}$ are also introduced to enhance the energy density of PLZST AFE ceramics.

Among these methods, modulating the Ti content is very effective to modifying the dielectric and energy storage properties of PLZST. For example, Liu et al. studied $\left(\mathrm{Pb}_{0.87} \mathrm{La}_{0.02} \mathrm{Ba}_{0.1}\right)\left(\mathrm{Zr}_{0.6} \mathrm{Sn}_{0.4}-x \mathrm{Ti}_{x}\right) \mathrm{O}_{3}$ systematically and the effects of Ti content on dielectric properties and phase transitions were summarized. ${ }^{14} \mathrm{Xu}$ et al. refined the phase diagram of $\mathrm{PbZr}_{1-x-y} \mathrm{Sn}_{x} \mathrm{Ti}_{y}$ and found the introduction of $\mathrm{Ti}$ would stabilize the FE order. ${ }^{15}$ However, the energy storage properties were not of much concern in the previous works.

Thus, in the present work, the effects of Ti content on dielectrics and energy storage properties of $\left(\mathrm{Pb}_{0.94} \mathrm{La}_{0.04}\right)$ $\left[\left(\mathrm{Zr}_{0.70} \mathrm{Sn}_{0.30}\right)_{1-x} \mathrm{Ti}_{x}\right] \mathrm{O}_{3}$ were studied systematically. The impacts of temperature rise on energy storage properties were analyzed. The charge-discharge experiments were taken to study the charge and energy releasing properties of PLZST ceramics.

\section{Experimental Procedures}

$\left(\mathrm{Pb}_{0.94} \mathrm{La}_{0.04}\right)\left[\left(\mathrm{Zr}_{0.70} \mathrm{~S} \mathrm{n}_{0.30}\right)_{1-x} \mathrm{Ti}_{x}\right] \mathrm{O}_{3}(x=0.10,0.12$, $0.14,0.16)$ (abbreviated as A0, A1, A2 and A3, respectively) ceramics were made by solid state reaction. The raw materials $\mathrm{Pb}_{3} \mathrm{O}_{4}, \mathrm{La}_{2} \mathrm{O}_{3}, \mathrm{ZrO}_{2}, \mathrm{SnO}_{2}$ and $\mathrm{TiO}_{2}$ with analytical purities were weighed with 2 wt.\% excess $\mathrm{Pb}_{3} \mathrm{O}_{4}$ and then mixed uniformly by ball milling. The mixtures were calcined at

This is an Open Access article published by World Scientific Publishing Company. It is distributed under the terms of the Creative Commons Attribution 4.0 (CC-BY) License. Further distribution of this work is permitted, provided the original work is properly cited. 


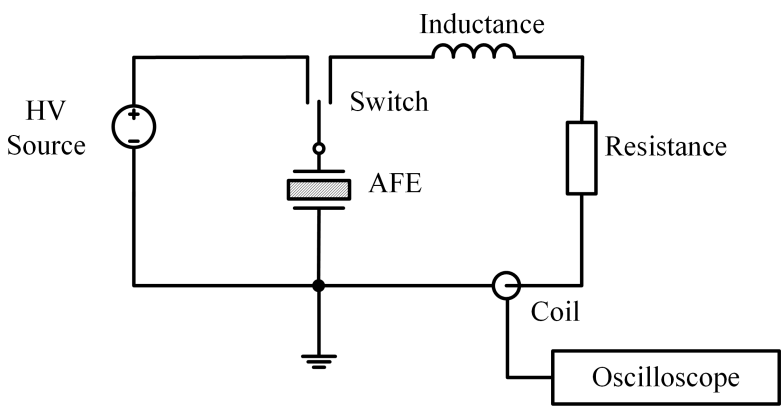

Fig. 1. Platform for measuring discharge current.

$850^{\circ} \mathrm{C}$ for $3 \mathrm{~h}$ and then ball milled again. After that, the powders were pressed to small disks and sintered at $1320^{\circ} \mathrm{C}$ for $2.5 \mathrm{~h}$. The obtained ceramics were polished and printed with silver electrodes.

The crystal structures of the ceramics were checked by X-ray diffraction (XRD, D/Max-2400, Rigaku Corporation, Japan) spectrums. The temperature dependence of dielectric constant $\left(\varepsilon_{r}-T\right)$ was measured by a precision LCR meter (4980A, Aglient, USA). The samples were housed in a chamber and could be heated up to $300^{\circ} \mathrm{C}$. The curves of polarization versus electric field $(P-E)$ were obtained by a FE analyzer (TF analyzer 2000, aixACCT, Germany). The charge-discharge properties were studied by a self-built platform as shown in Fig. 1. The ceramics were charged by a DC high voltage (HV) source and then discharged via an LRC circuit. A high voltage bidirectional switch was used to change the samples between charge and discharge state. A high speed oscilloscope (DPO 4104, Tektronix, USA) connected with a coil (6585, Pearson Electronics, USA) would capture the waveform of discharge current.

\section{Results and Discussion}

The XRD spectra of the A0-A3 PLZST ceramics are shown in Fig. 2. There is no secondary phase and a single perovskite structure phase is obtained. The splitting (200) and (002) peaks when $x=0.10$ indicate that the crystal structure is tetragonal.

Figure 3 shows the curves of temperature versus dielectric constant $\left(\varepsilon_{r}-T\right)$. Generally, with increasing Ti content, the Curie temperature $T_{c}$ which corresponds to the peak of the curves decreases and the maximum $\varepsilon_{r}$ increases. Above $T_{c}$, the dielectrics will be transformed to paraelectric (PE) state.

The $P-E$ curves of A0-A3 ceramics are shown in Fig. 4. When $x<0.16$, the obtained ceramics are under AFE state at room temperature. With increasing $\mathrm{Ti}$ content, the forward and backward phase transition field $\left(E_{\mathrm{AFE}-\mathrm{FE}}\right.$ and $\left.E_{\mathrm{FE}-\mathrm{AFE}}\right)$ both decrease. In $\mathrm{A} 0$, the forward transition field $E_{\mathrm{AFE}-\mathrm{FE}}$ is too high that the ceramics will break down before the FE state is induced. When $x=0.16$, there will be no double hysteresis loops and the $P-E$ curve indicates that A3 is under FE state at room temperature.

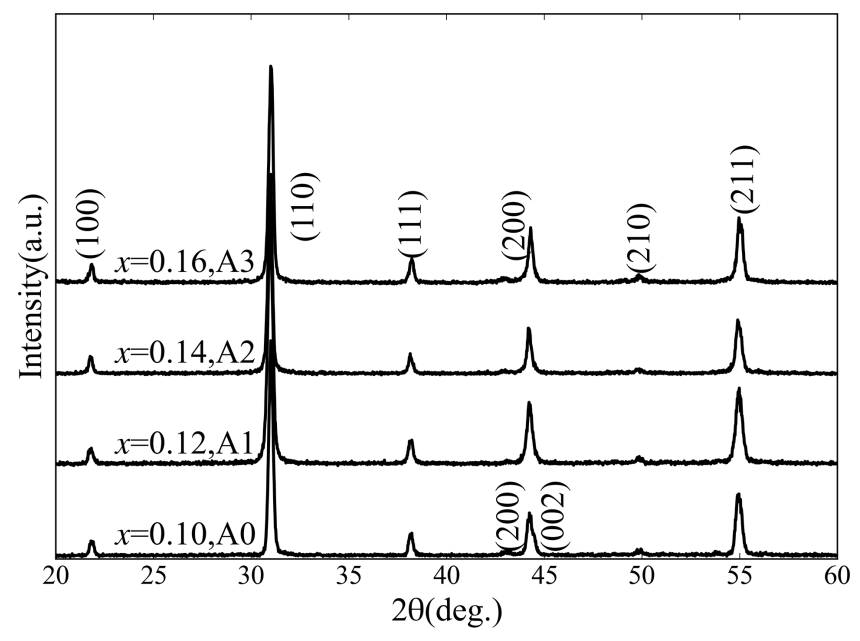

Fig. 2. XRD patterns of A0-A3 ceramics.

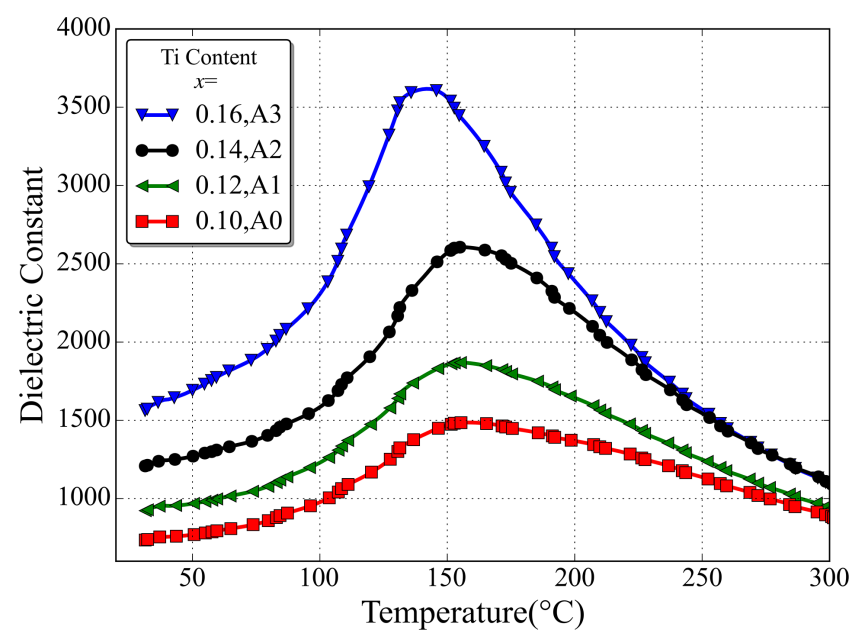

Fig. 3. Temperature dependence of dielectric constant.

The different $P-E$ curves will result in significant variation of energy storage properties. For AFE or FE materials, the energy stored in the charge process $W_{\text {st }}$ could be calculated as

$$
W_{\mathrm{st}}=\int_{0}^{P_{\max }} E d P,
$$

where $P_{\max }$ is the maximum polarization. Under discharge process, the stored energy will not be released completely and is calculated as

$$
W_{\mathrm{re}}=-\int_{P_{\max }}^{P_{r}} E d P=\int_{P_{r}}^{P_{\max }} E d P<W_{\mathrm{st}},
$$

where $P_{r}$ is the remanent polarization. In Fig. 4, the green shade area represents the releasable energy density. The energy efficiency $\eta$ is defined as the ratio between $W_{\text {re }}$ and $W_{\text {st }}$

$$
\eta=\frac{W_{\text {re }}}{W_{\text {st }}} \times 100 \% \text {. }
$$




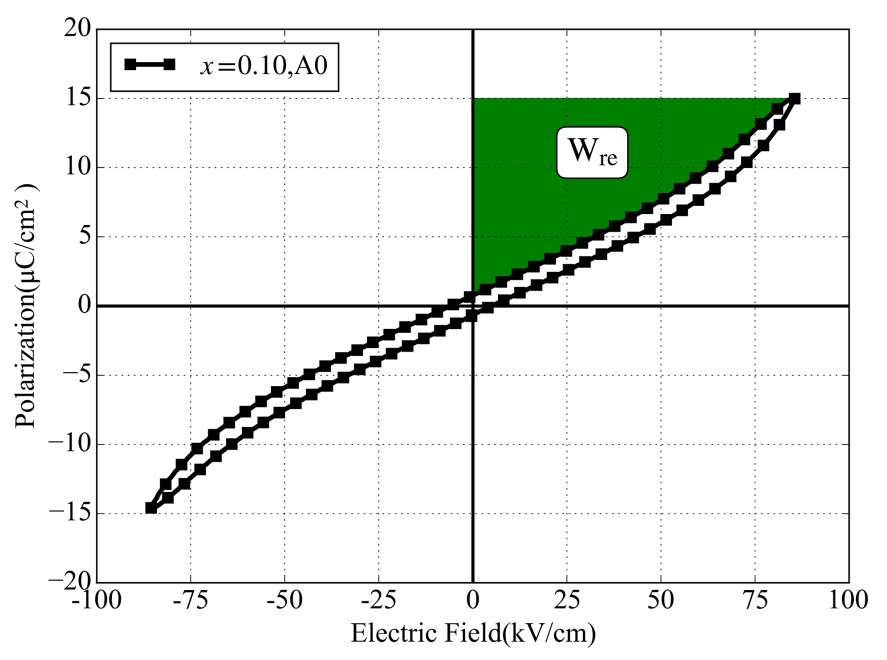

(a)

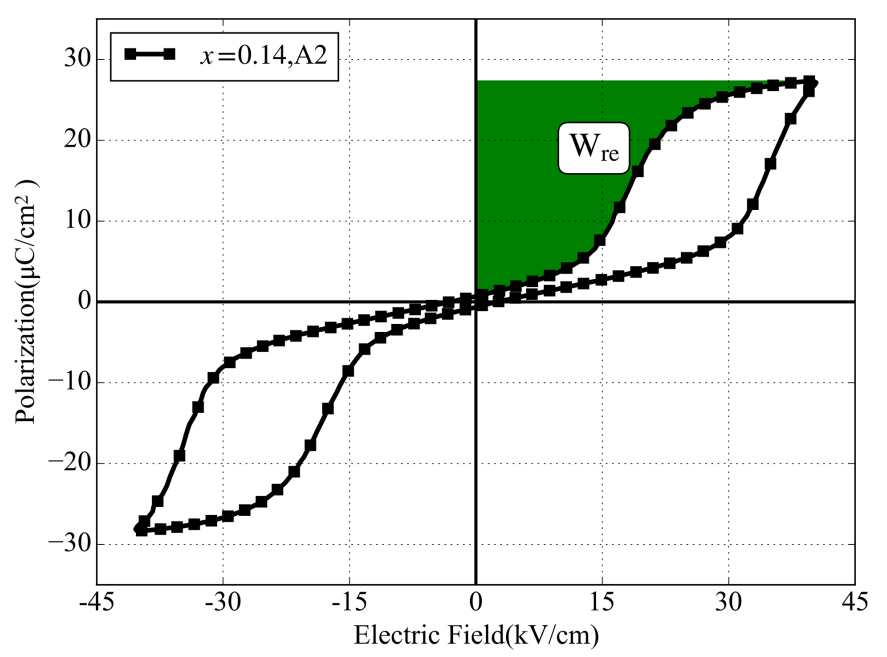

(c)

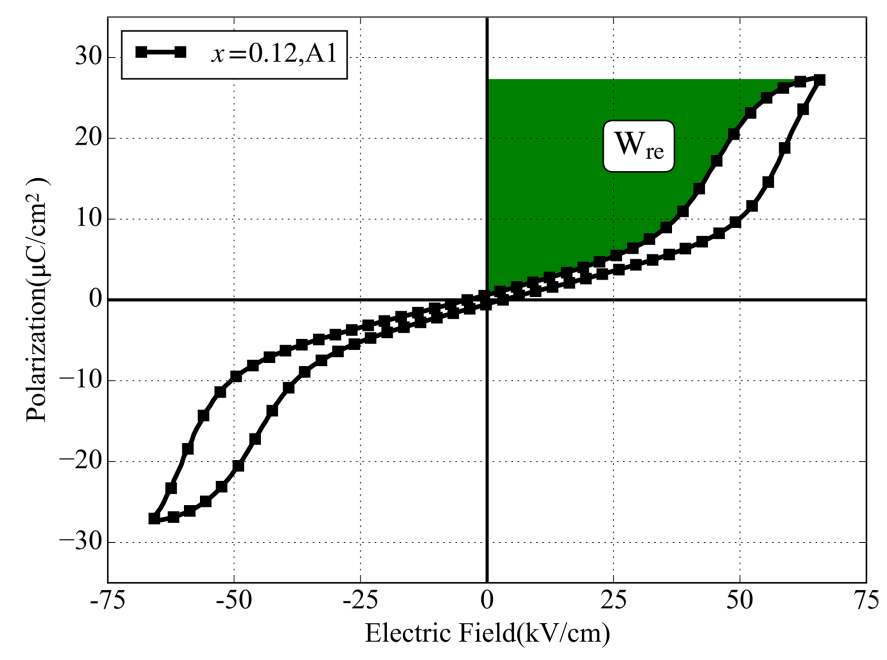

(b)

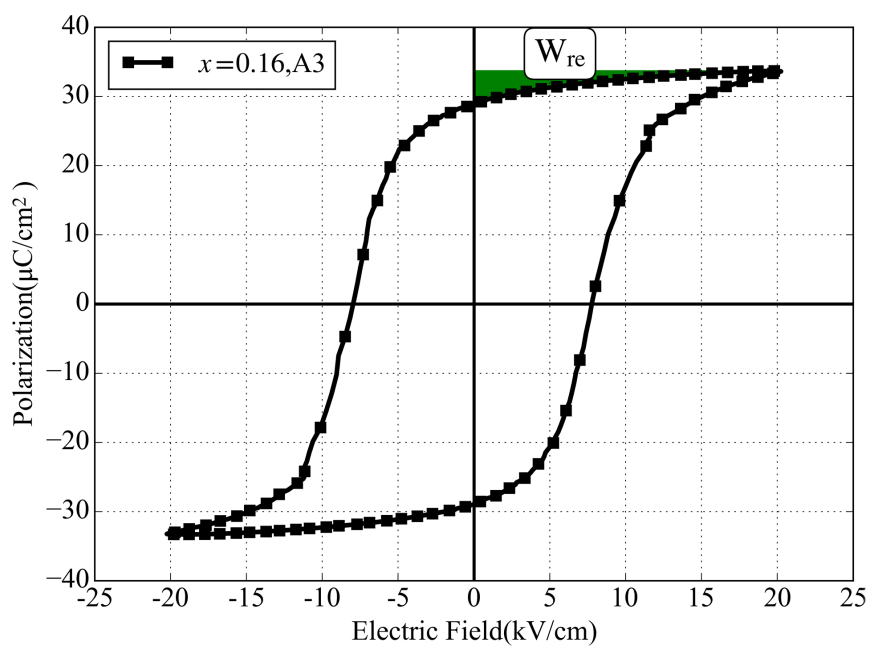

(d)

Fig. 4. Hysteresis loops of (a) A0, (b) A1, (c) A2 and (d) A3 ceramics.

The releasable energy density $W_{\text {re }}$ and efficiency of A0-A3 under different electric fields are illustrated in Fig. 5.

For A3 composition, $W_{\text {re }}$ is only $0.03 \mathrm{~J} / \mathrm{cm}^{3}$ under $20 \mathrm{kV} /$ $\mathrm{mm}$ though $W_{\text {st }}$ could be as high as $0.53 \mathrm{~J} / \mathrm{cm}^{3}$ (not shown here). Consequently, the energy efficiency is only about $5.7 \%$ under $20 \mathrm{kV} / \mathrm{cm}$. Two reasons contribute to the low $W_{\text {re }}$ in A3: the polarization tends to be saturated under low electric field and the remanent polarization $P_{r}$ is very large. Thus, the releasable energy density of A3 is the lowest though it has the highest $P_{\max }$.

The highest $W_{\text {re }}$ is achieved when $x=0.12$ and is about $1.03 \mathrm{~J} / \mathrm{cm}^{3}$ under $65.7 \mathrm{kV} / \mathrm{cm}$. Meanwhile, the efficiency is still high (about 80\%). Thus, the A1 composition may have potential for capacitors. Also, for A1 and A2, larger increment of releasable energy density could be observed near the phase transition field. This could be attributed to the sharp increase of polarization due to the induced AFE-FE phase transition by external electric field. ${ }^{16}$ When $x=0.10$, the ceramics break down under $85 \mathrm{kV} / \mathrm{cm}$ before the FE state could be induced. Thus, for AFE materials, the break down strength (BDS) is also vital for high energy density. If the BDS of A0 could be enhanced by some methods, such as hot press sintering and SPS, higher energy density would be achieved.

Temperature stability is also important for capacitors because they often work in a wide temperature range. ${ }^{3}$ Thus, the hysteresis loops of A1 and A3 at different temperatures were measured and are shown in Fig. 6.

For A1 composition, the maximum polarization $P_{\max }$ and forward phase transition field $E_{\mathrm{AFE}-\mathrm{FE}}$ decrease with temperature rise. However, the backward phase transition field would increase firstly and then decrease. Another remarkable phenomenon is that the hysteresis loop becomes "slimmer". The temperature dependence of $W_{\text {re }}$ of $\mathrm{A} 1$ is 


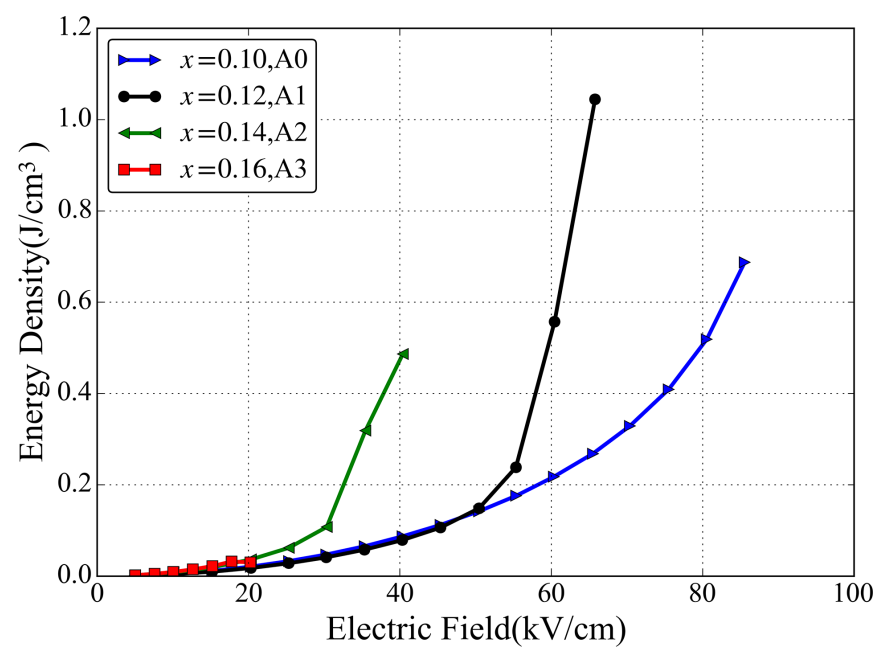

(a)

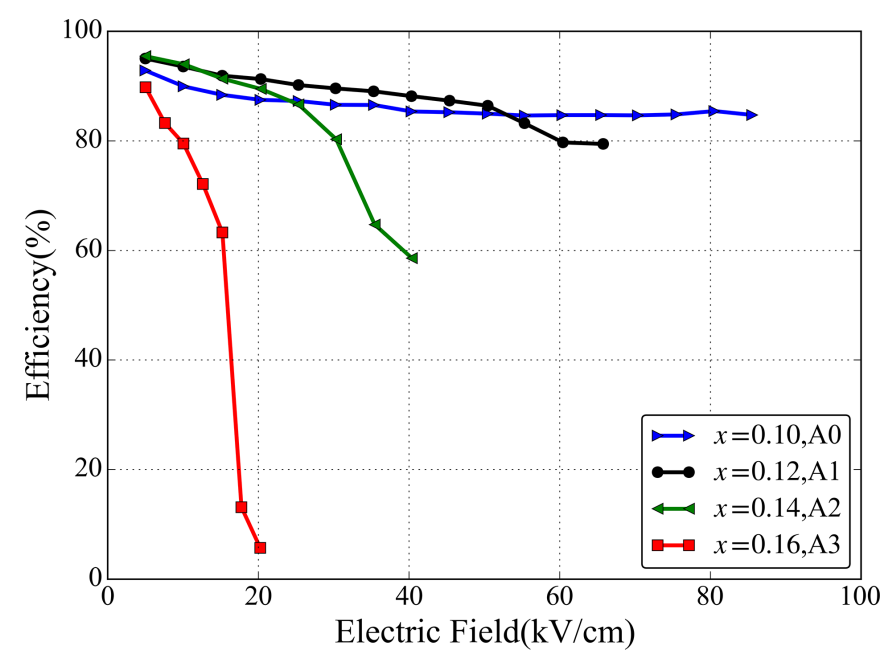

(b)

Fig. 5. (a) Releasable energy density and (b) efficiency of A0-A3 under different electric fields.

shown in Fig. 7(a). It is interesting to see that $W_{\text {re }}$ will firstly increase and then decrease. At $40^{\circ} \mathrm{C}, W_{\text {re }}$ will reach maximum and is about $1.06 \mathrm{~J} / \mathrm{cm}^{3}$. This is due to the increase of $E_{\mathrm{FE}-\mathrm{AFE}}$ at beginning. Thus, though $P_{\max }$ declines, $W_{\text {re }}$ will still rise from $1.03 \mathrm{~J} / \mathrm{cm}^{3}$ at $22^{\circ} \mathrm{C}$ to $1.06 \mathrm{~J} / \mathrm{cm}^{3}$ at $40^{\circ} \mathrm{C}$. Above $40^{\circ} \mathrm{C}, W_{\text {re }}$ will keep declining with increasing temperature. At $80^{\circ} \mathrm{C}$ and $100^{\circ} \mathrm{C}$, the decreasing rate of $W_{\text {re }}$ is about $6.8 \%$ and $16.5 \%$, respectively, which indicates that $\mathrm{A} 1$ composition has promising temperature stability. At $140^{\circ} \mathrm{C}$, the dielectrics tend to be PE state and linear dielectrics because the $P-E$ curve is almost like a straight line. As to efficiency $\eta$, it keeps rising with increasing temperature because the hysteresis loop becomes "slimmer", which is shown in Fig. 7(b).

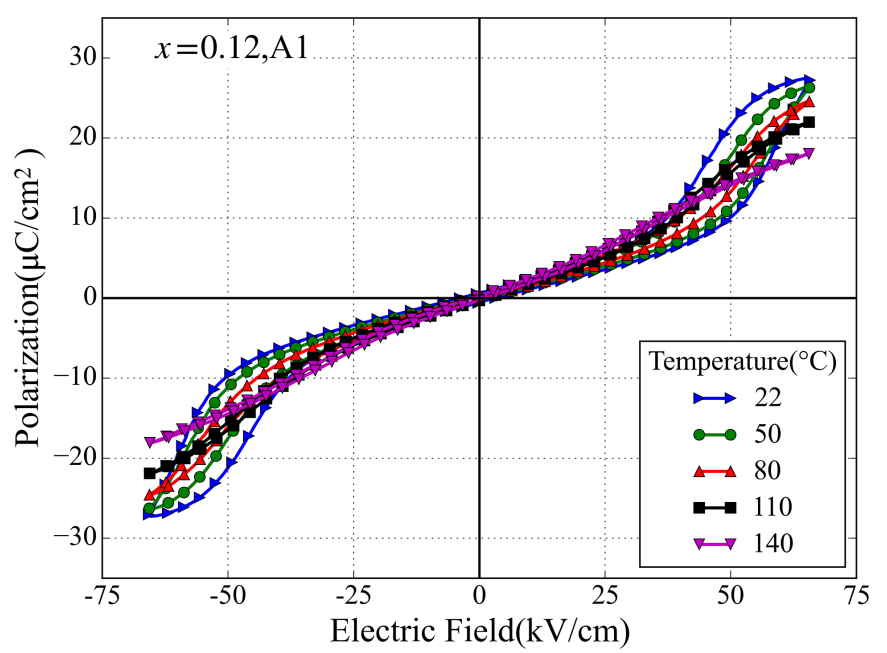

(a)
For A3 composition, the result is quite different. It could be seen that the $P-E$ curve changes from single hysteresis loop to double hysteresis loop and then tends to be a straight line. This indicates the phase transition from FE to AFE and then to PE state. Consequently, the releasable energy density $W_{\text {re }}$ would increase due to the FE-AFE transition and then decrease due to AFE-PE transition. Along with the phase transition, the efficiency $\eta$ jumps from $5.7 \%$ at $22^{\circ} \mathrm{C}$ to higher than $90 \%$ above $100^{\circ} \mathrm{C}$.

Based on the above results, to enhance the temperature stability, the dielectrics should be under AFE state in a wide temperature range. Usually, the stability above room temperature is only considered because it is not easy to measure the $P-E$ curves at low temperature. However, some

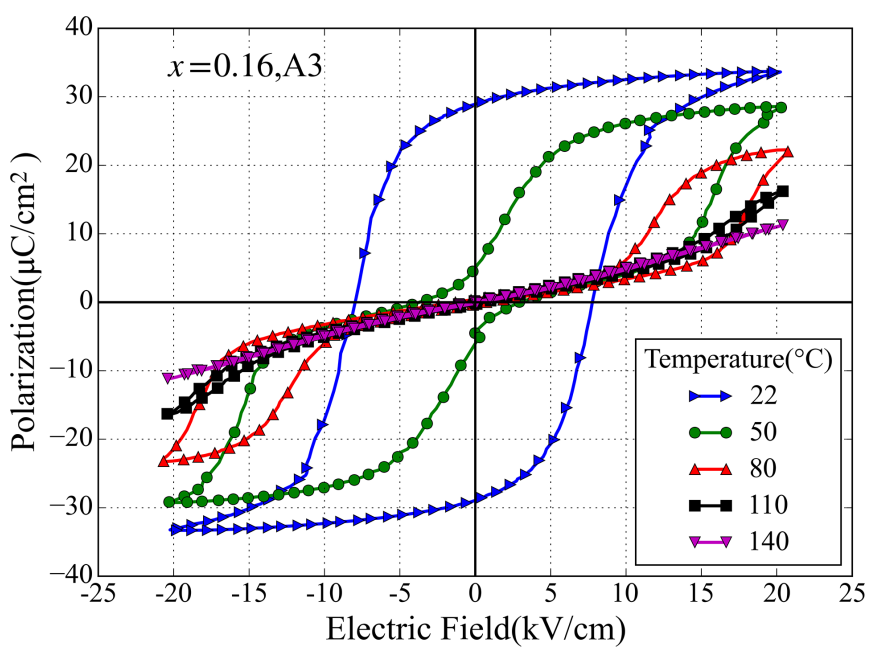

(b)

Fig. 6. Hysteresis loops of (a) A1 and (b) A3 under different temperatures. 


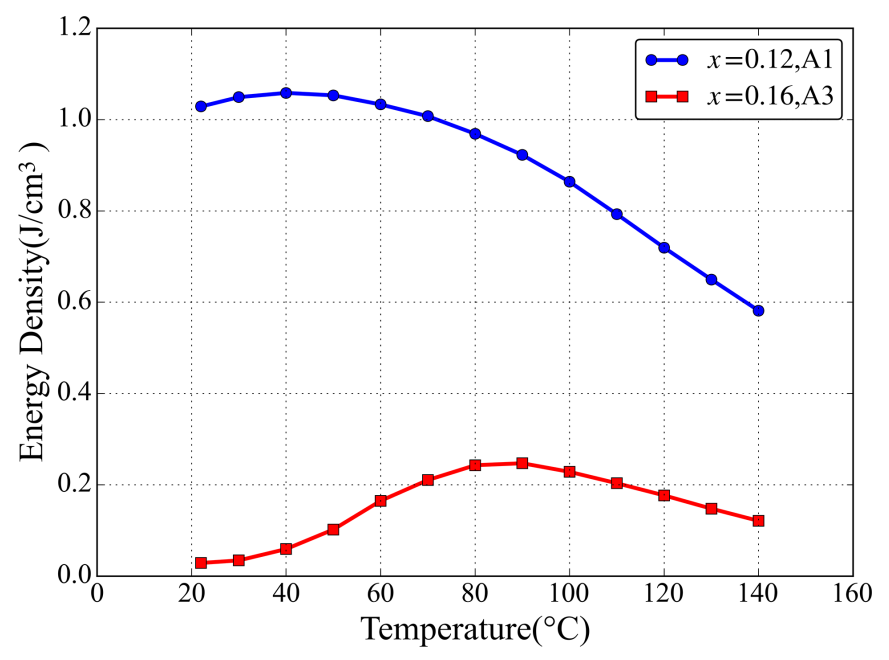

(a)

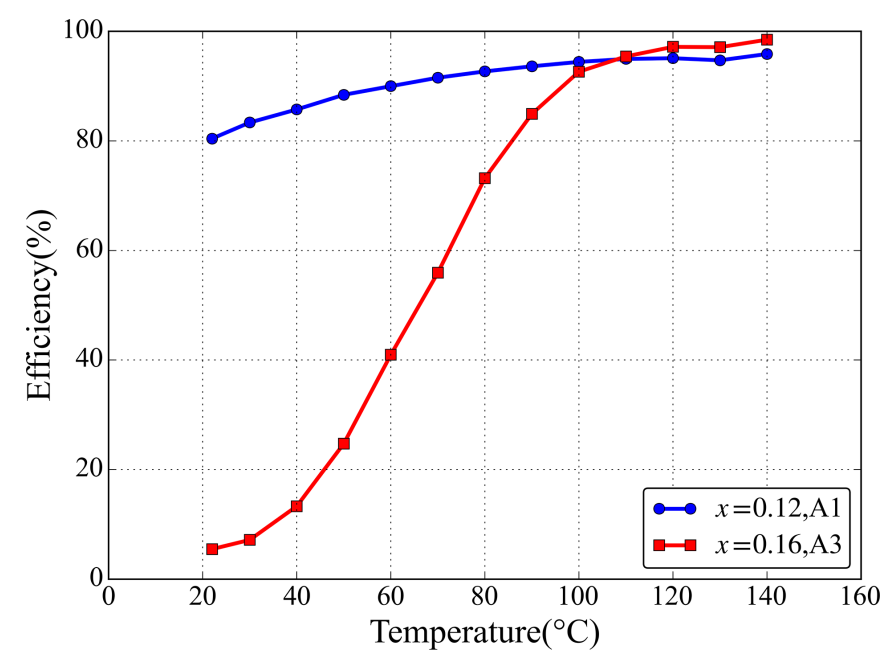

(b)

Fig. 7. Temperature dependence of (a) releasable energy density and (b) efficiency of A1 and A3.

dielectrics may be under AFE state at room temperature and will turn into $\mathrm{FE}$ state below room temperature. Inferring from the results of $\mathrm{A} 3$, the FE-AFE transition induced by temperature declination would result in sharp decrease of energy density and efficiency. Consequently, the temperature stability below room temperature is also significant and should be considered if the capacitors work at low temperature.

The discharge current of $\mathrm{A} 2$ and $\mathrm{A} 3$ is also measured to study the different discharge properties of AFE and FE dielectrics and is shown in Fig. 8. The shaking of the current may result from the mechanical switch. The current amplitude $I_{\max }$ of A2 is much higher than that of A3 and the discharge period is also much longer. As a result, the released charge $Q_{\mathrm{dis}}$ and energy $W_{\mathrm{dis}}$ in the discharge process of A2 will be much higher. $Q_{\text {dis }}$ and $W_{\text {dis }}$ can

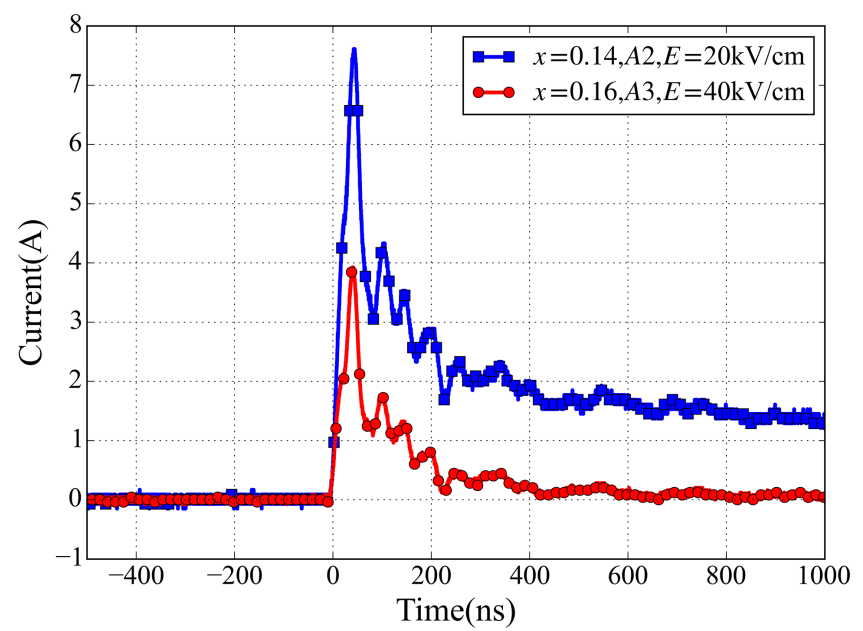

Fig. 8. Discharge current of A2 and A3. be calculated as

$$
\begin{gathered}
Q_{\mathrm{dis}}=\int I d t, \\
W_{\mathrm{dis}}=R \int I^{2} d t / V=R \int I^{2} d t /(d \cdot S),
\end{gathered}
$$

where $I, R$ and $t$ are current, resistance and time, respectively. $V, d$ and $S$ are volume, thickness $(0.4 \mathrm{~mm})$ and electrodes' area $\left(0.1808 \mathrm{~cm}^{2}\right)$ of the ceramics. Also, the stored charge $Q_{\mathrm{st}}$ in the charge process can be calculated from the hysteresis loop and is

$$
Q_{\mathrm{st}}=P_{\max } \cdot S .
$$

Table. 1 lists some parameters of A2 and A3

For A2 composition, the stored charge $Q_{\mathrm{st}}$ is about $4.9 \mu \mathrm{C}$ calculated from the $P-E$ curve. The released charge $Q_{\text {dis }}$ calculated from discharge current is about $5.0 \mu \mathrm{C}$. $Q_{\text {dis }}$ is a bit higher than $Q_{\mathrm{st}}$, which may result from experimental error and the different charge time. However, ignoring the small difference, $Q_{\text {dis }}$ is quite close to $Q_{\text {st }}$, which means the stored charge could be released almost completely in A2 AFEs. This could be attributed to the low remanent polarization $P_{r}$ of AFE dielectrics. The discharge energy density $W_{\text {dis }}$ is much lower than releasable energy density $W_{\text {re }}$, which has been explained by the different depolarization process under quasistatic and transient situation. ${ }^{17}$

For A3 composition, it has higher $Q_{\text {st }}(6.1 \mu \mathrm{C})$, but only

\begin{tabular}{|c|c|c|c|c|c|c|}
\hline Composition & $\begin{array}{c}E_{\max } \\
(\mathrm{kV} / \mathrm{cm})\end{array}$ & $I_{\max }(\mathrm{A})$ & $Q_{\mathrm{st}}(\mu \mathrm{C})$ & $Q_{\text {dis }}(\mu \mathrm{C})$ & $\begin{array}{c}W_{\mathrm{re}} \\
\left(\mathrm{J} / \mathrm{cm}^{3}\right)\end{array}$ & $\begin{array}{c}W_{\mathrm{dis}} \\
\left(\mathrm{J} / \mathrm{cm}^{3}\right)\end{array}$ \\
\hline A2 (AFE) & 40 & 7.6 & 4.9 & 5.0 & 0.48 & 0.22 \\
\hline A3 (FE) & 20 & 3.9 & 6.1 & 0.5 & 0.03 & 0.02 \\
\hline
\end{tabular}
very little charge $\left(Q_{\mathrm{dis}}=0.5 \mu \mathrm{C}\right)$ could be released in the fast

Table 1. Discharge parameters of A2 and A3. 
discharge process. Apparently, this is due to the large remanent polarization $P_{r}$ of $\mathrm{FE}$ materials. Also, the discharge energy density $W_{\text {dis }}$ is lower than releasable energy density $W_{\text {re }}$. Thus, for dielectrics of capacitors, the remanent polarization $P_{r}$ should be as low as possible, which would enhance the energy and charge releasing efficiency.

\section{Conclusions}

The dielectric and energy storage properties of $\left(\mathrm{Pb}_{0.94} \mathrm{La}_{0.04}\right)$ $\left[\left(\mathrm{Zr}_{0.70} \mathrm{Sn} 0.3_{0}\right)_{1-x} \mathrm{Ti}_{x}\right] \mathrm{O}_{3}$ composition with different $\mathrm{Ti}$ content were studied. High releasable energy density of $1.03 \mathrm{~J} /$ $\mathrm{cm}^{3}$ was obtained when $x=0.12$ under $65.7 \mathrm{kV} / \mathrm{cm}$. Increasing $\mathrm{Ti}$ content results in decreasing transition field and when $x=0.16$, the composition will be under FE state at room temperature. Also, with increasing temperature, the phase transition from FE to AFE and then to PE was confirmed when $x=0.16$. The discharge experiment proves that the charge stored in AFE materials can be released much more completely than that in FE dielectrics.

\section{Acknowledgments}

This work is supported by "111" Project (B14040), the National 973 Project of China under Grant No. 2015CB654602, the National Science Foundation of China (NSAF) under Grant no. U1230116 and International Science \& Technology Cooperation Program of China under Grant No. 2015 DFA51100.

\section{References}

${ }^{1}$ E. J. Matthews, M. Kristiansen and A. A. Neuber, Capacitor evaluation for compact pulsed power, IEEE Trans. Plasma Sci. 38, 500 (2010).

${ }^{2}$ Y. P. Liang, D. M. Wang, L. L. Gao and D. H. Liu, Calculation of temperature field in power capacitor, IEEE Trans. Ind. Electron. 62, 2788 (2015).

${ }^{3}$ Z. Liu, X. F. Chen, W. Peng, C. H. Xu, X. L. Dong, F. Cao and G. S. Wang, Temperature-dependent stability of energy storage properties of $\mathrm{Pb}_{0.97} \mathrm{La}_{0.02}\left(\mathrm{Zr}_{0.58} \mathrm{Sn}_{0.335} \mathrm{Ti}_{0.085}\right) \mathrm{O}_{3}$ antiferroelectric ceramics for pulse power capacitors, Appl. Phys. Lett. 106, 262901 (2015).

${ }^{4}$ J. Ge, G. Pan, D. Remiens, Y. Chen, F. Cao, X. L. Dong and G. S. Wang, Effect of electrode materials on the scaling behavior of energy density in $\mathrm{Pb}\left(\mathrm{Zr}_{0.96} \mathrm{Ti}_{0.03}\right) \mathrm{Nb}_{0.01} \mathrm{O}_{3}$ antiferroelectric films, Appl. Phys. Lett. 101, 112905 (2012).
${ }^{5}$ X. F. Chen, H. L. Zhang, F. Cao, G. S. Wang, X. L. Dong, Y. Gu, H. L. He and Y. S. Liu, Charge-discharge properties of lead zirconate stannate titanate ceramics, J. Appl. Phys. 106, 034105 (2009).

${ }^{6}$ R. Xu, Z. Xu, Y. J. Feng, H. L. He, J. J. Tian and K. Yu, Fatigue resistance of $\mathrm{Pb}_{0.90} \mathrm{La}_{0.04} \mathrm{Ba}_{0.04}\left[\left(\mathrm{Zr}_{0.6} \mathrm{Sn}_{0.4}\right)_{0.85} \mathrm{Ti}_{0.15}\right] \mathrm{O}_{3}$ antiferroelectric ceramics under fast charge-discharge cycling, Ceram. Int. 42, 9094 (2016).

${ }^{7}$ X. H. Hao, A review on the dielectric materials for high energystorage application, J. Adv. Dielectr. 03, 1330001 (2013).

${ }^{8}$ C. H. Xu, Z. Liu, X. F. Chen, S. G. Yan, F. Cao, X. L. Dong and G. S. Wang, High charge-discharge performance of $\mathrm{Pb}_{0.98} \mathrm{La}_{0.02}$ $\left(\mathrm{Zr}_{0.35} \mathrm{Sn}_{0.55} \mathrm{Ti}_{0.10}\right)_{0.995} \mathrm{O}_{3}$ antiferroelectric ceramics, J. Appl. Phys. 120, 074107 (2016).

${ }^{9}$ Y. J. Feng, Z. Xu, H. G. Li and X. Yao, Effect of La modifier on the electric hysteresis of lead zirconate stannate titanate compounds, Ceram. Int. 30, 1393 (2004).

${ }^{10}$ L. Zhang, S. L. Jiang, B. Y. Fan and G. G. Zhang, High energy storage performance in $\left(\mathrm{Pb}_{0.858} \mathrm{Ba}_{0.1} \mathrm{La}_{0.02} \mathrm{Y}_{0.008}\right)\left(\mathrm{Zr}_{0.65} \mathrm{Sn}_{0.3} \mathrm{Ti}_{0.05}\right)$ $\mathrm{O}_{3}-\left(\mathrm{Pb}_{0.97} \mathrm{La}_{0.02}\right)\left(\mathrm{Zr}_{0.9} \mathrm{Sn}_{0.05} \mathrm{Ti}_{0.05}\right) \mathrm{O}_{3}$ anti-ferroelectric composite ceramics, Ceram. Int. 41, 1139 (2015).

${ }^{11}$ S. C. Chen, T. Q. Yang, J. F. Wang and X. Yao, Effects of glass additions on energy storage performance of $\left(\mathrm{Pb}_{0.97} \mathrm{La}_{0.02}\right)$ $\left(\mathrm{Zr}_{0.92} \mathrm{Sn}_{0.05} \mathrm{Ti}_{0.03}\right) \mathrm{O}_{3}$ antiferroelectric thick films, J. Adv. Dielectr. 03, 1350012 (2013).

${ }^{12}$ G. Z. Zhang, D. Y. Zhu, X. S. Zhang, L. Zhang, J. Q. Yi, B. Xie, Y. K. Zeng, Q. Li, Q. Wang and S. L. Jiang, High-energy storage performance of $\left(\mathrm{Pb}_{0.87} \mathrm{Ba}_{0.1} \mathrm{La}_{0.02}\right)\left(\mathrm{Zr}_{0.68} \mathrm{Sn}_{0.24} \mathrm{Ti}_{0.08}\right) \mathrm{O}_{3}$ antiferroelectric ceramics fabricated by the hot-press sintering method, J. Am. Ceram. Soc. 98, 1175 (2015).

${ }^{13}$ L. Zhang, S. L. Jiang, B. Y. Fan and G. Z. Zhang, Enhanced energy storage performance in $\left(\mathrm{Pb}_{0.858} \mathrm{Ba}_{0.1} \mathrm{La}_{0.02} \mathrm{Y}_{0.008}\right)\left(\mathrm{Zr}_{0.65}\right.$ $\left.\mathrm{Sn}_{0.3} \mathrm{Ti}_{0.05}\right) \mathrm{O}_{3}-\left(\mathrm{Pb}_{0.97} \mathrm{La}_{0.02}\right)\left(\mathrm{Zr}_{0.9} \mathrm{Sn}_{0.05} \mathrm{Ti}_{0.05}\right) \mathrm{O}_{3}$ anti-ferroelectric composite ceramics by spark plasma sintering, J. Alloys Compd. 622, 162 (2015).

${ }^{14} \mathrm{P}$. Liu and $\mathrm{X}$. Yao, Dielectric properties and phase transitions of $\left(\mathrm{Pb}_{0.87} \mathrm{La}_{0.02} \mathrm{Ba}_{0.1}\right)\left(\mathrm{Zr}_{0.6} \mathrm{Sn}_{0.4-x} \mathrm{Ti}_{x}\right) \mathrm{O}_{3}$ ceramics with compositions near AFE/RFE phase boundary, Solid State Commun. 132, 809 (2004).

${ }^{15}$ Y. H. Xu, G. D. Wang, R. Xu, B. B. Xie and Y. J. Feng, Refining the phase diagram of $\mathrm{PbZr}_{1-x-y} \mathrm{Sn}_{x} \mathrm{Ti}_{y} \mathrm{O}_{3}$ ceramics with $0.40 \leq$ $x \leq 0.54$ by crystal structural, dielectric response and hysteresis loop investigations, Ceram. Int. 42, 9926 (2016).

${ }^{16}$ H. L. Zhang, X. F. Chen, F. Cao, G. S. Wang, X. L. Dong, Z. Y. $\mathrm{Hu}$ and T. Du, Charge-discharge properties of an antiferroelectric ceramics capacitor under different electric fields, J. Am. Ceram. Soc. 93, 4015 (2010).

${ }^{17}$ R. Xu, Z. Xu, Y. J. Feng, X. Y. Wei, J. J. Tian and D. Huang, Evaluation of discharge energy density of antiferroelectric ceramics for pulse capacitors, Appl. Phys. Lett. 109, 224103 (2016). 